\title{
Perceptions of Program Directors on the Necessity of Hepatopancreaticobiliary Fellowships in Training General Surgery Residents
}

\author{
Neelima Rehil, Lauren Smithson and Vijay Mittal \\ Department of General Surgery, Providence Hospital and Medical Centers, Wayne State University, Southfield, Michigan 48075, \\ USA
}

\begin{abstract}
Objective: To determine the perceptions of general surgery PDs (program directors) concerning the necessity for HPB (hepatopancreatobiliary) fellowships to practicing HPB surgery. Methods: A 22-question electronic survey was sent to 250 general surgery PDs recognized by the American Association of Medical Colleges in the United States regarding the experience and competency of graduating general surgery residents. Survey included qualitative and quantitative responses in multiple choice and write-in format. Results: Eighty-one PDs responded (32\%): $74 \%$ from university affiliated programs and $26 \%$ from community programs. $80 \%$ did not have an HPB fellowship. $66 \%$ had no HPB service for general surgery residents.40\% of PDs felt that residents performed 11-25 hepatic, pancreatic and biliary cases, and some were performing > 40 complex hepatic, pancreatic and biliary cases. Two-thirds of PDs were confident that graduating residents could perform pancreaticoduodenectomies and liver resections independently; $100 \%$ believed that residents could perform distal pancreatectomies. A majority of PDs felt that residents could be certified to perform HPB surgery without fellowship training. Conclusions: Current opinion amongst general surgery PDs suggests that general surgery residents perform more than the ACGME (Accreditation Council for Graduate Medical Education) required number of complex HPB cases and should be individually assessed for competence in HPB without the need for further training.
\end{abstract}

Key words: Hepatopancreatobiliary education, fellowship, resident competency.

\section{Introduction}

The ACGME (Accreditation Council for Graduate Medical Education), which governs medical education at the resident level, requires all general surgery residents to perform a total of 750 cases over the course of a 5-year program, with a requirement of four major liver and three major pancreas cases. The AHPBA (American Hepatopancreatobiliary Association), which is the model for the IHPBA (International Hepatopancreatobiliary Association) fellowship standards, requires that fellows complete a total of 100 major HPB (hepatopancreatobiliary) operations in a minimum of 12 months [1]. The fellow is required to be

Corresponding author: Vijay Mittal, MD, FACS, research field: education and hepatopancreatobiliary. E-mail: vijay.mittal@providence-stjohnhealth.org. the "primary surgeon" in 70 of these cases and the operations should consist of the details included in Appendix A. According to recent literatures, general surgery residents are meeting some of these fellowship requirements during their 5-year of residency [2]. Opinions are varied regarding the competence of general surgery residents in performing HPB surgery out of residency. There is no required training for general surgeons to perform HPB cases. Although hospital privileges depend on surgeon experience, HPB patients require particular care and perioperative studies for complete assessment and improved outcomes. Whether or not an HPB fellowship is the answer to improved HPB care remains in question. This study aimed to determine the perceptions that general surgery PDs (program directors) have regarding the necessity of HPB fellowships, and 
whether general surgery training sufficiently prepares graduating residents for the inclusion of HPB cases in their practice.

\section{Methods}

A 21 question electronic survey was sent to the PDs of the 250 general surgery residency programs recognized by the American Association of Medical Colleges in the United States (Appendix B). The questions identified the nature of the residency program, the number of HPB surgeons employed, the types of HPB cases, the complex HPB cases that graduating residents could perform, and the opinions of PDs on the future of HPB fellowship training.

\section{Results}

\subsection{Survey Respondent Demographics}

Eighty-one PDs responded to the survey, resulting in a $32 \%$ response rate. Forty-two $(52 \%)$ of those were directors of university programs, 21 (26\%) were at community programs, and $18(22 \%)$ practiced at a combined program. In these programs, a majority (53\%) graduated three to five general surgery residents per year, $36 \%$ had more than five graduates, and $11 \%$ had one or two.

Eighty percent of responding programs did not have an associated HPB fellowship at their institution. The teaching faculty performing HPB surgery is outlined in Table 1.

\subsection{Resident Exposure to HPB Caseloads}

Sixty-three percent of residents were exposed to HPB surgery as post-graduate years one or two. By the end of five years of training, 38\%-44\% of residents were exposed to between 11 and 25 complex pancreatic, hepatic, and biliary surgeries (Table 2).

Six percent of programs had residents performing over 40 complex biliary cases (Table 2). Thirteen percent of programs had residents performing more than 40 pancreas cases, and $22 \%$ of programs had residents performing more than 40 liver cases prior to graduation. These numbers were obtained even though only $34 \%$ of respondents had a specific HPB service on which residents rotated. PDs felt that their graduating general surgery residents were able to perform certain complex HPB surgeries with variable frequencies (Table 3). Chi square was performed analyzing each liver, pancreas and biliary case that PDs found their resident to be most capable of performing at the time of graduation. In doing this analysis, no statistical significance separated graduates from academic, community or combined programs $\left(X^{2}=1.132, P=\right.$ 0.889).

\subsection{Competency of Graduating Residents in HPB}

Sixty-seven percent of programs had less than $5 \%$ of their residents entering HPB fellowships over the last ten years. PDs feel that HPB fellowships are necessary

Table 1 Details of general surgery residency faculty involvement in HPB training and exposure.

\begin{tabular}{lll}
\hline Number of faculty surgeons $(N)$ & $\begin{array}{l}\text { Percentage of faculty performing regular HPB } \\
\text { surgery }(\%)\end{array}$ & $\begin{array}{l}\text { Percentage of general surgery faculty with } \\
\text { formal HPB training }(\%)\end{array}$ \\
\hline $1-2$ & 41 & 81 \\
$3-5$ & 39 & 18 \\
$6-10$ & 17 & 2 \\
\hline
\end{tabular}

Table 2 Number of complex HPB cases completed by general surgery residents.

\begin{tabular}{llll}
\hline $\begin{array}{l}\text { Number of HPB } \\
\text { cases by type }(N)\end{array}$ & $\begin{array}{l}\text { Percentage of institutions attaining } \\
\text { indicated liver numbers }(\%)\end{array}$ & $\begin{array}{l}\text { Percentage of institutions attaining } \\
\text { indicated pancreas numbers }(\%)\end{array}$ & $\begin{array}{l}\text { Percentage of institutions attaining } \\
\text { indicated biliary numbers }(\%)\end{array}$ \\
\hline$<10$ & 40 & 31 & 35 \\
$11-25$ & 40 & 38 & 44 \\
$26-40$ & 9 & 18 & 5 \\
$>40$ & 22 & 13 & 6 \\
\hline
\end{tabular}


Table 3 Complex HPB cases that PDs feel their graduating general surgery residents are capable of performing.

\begin{tabular}{ll}
\hline Case & PD confidence in residents safely performing HPB procedures $(\%)$ \\
\hline Liver & 99 \\
Laparoscopic or open liver biopsy & 66 \\
Liver resection/segmentectomy & 23 \\
Right or left hepatectomy & \\
Pancreas & 100 \\
Distal pancreatectomy & 65 \\
Whipple procedure & 10 \\
Central pancreatectomy & 8 \\
Laparoscopic pancreatectomy & \\
Biliary & 85 \\
Common bile duct exploration & 85 \\
Common bile duct anastomosis & 81 \\
Repair of bile duct in trauma setting & 21 \\
Excision of cholangiocarcinoma &
\end{tabular}

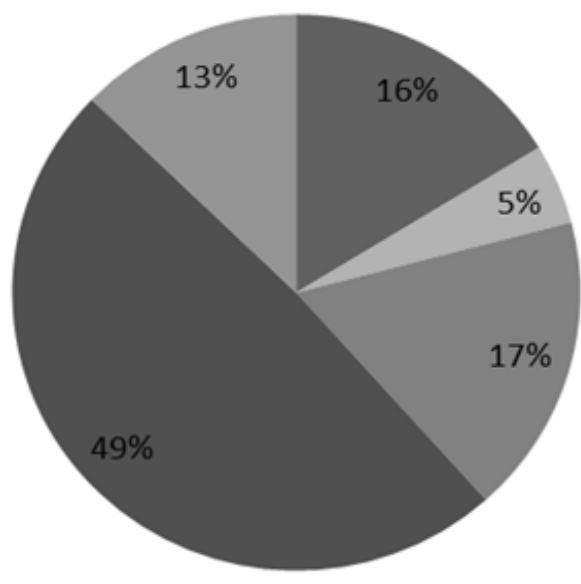

All GS residents

Only for community hospital graduates

Only if entering university hospital to perform HPB surgery

Only those with interested in HPB

\section{Unnecessary}

Fig. 1 Perspective of PD on general surgery residents requiring HPB fellowship training.

only for those residents who showed an interest in HPB surgery (49\%) (Fig. 1). Fifty-nine percent of PDs felt that after five years of general surgery, residents were competent enough to perform HPB surgery, either immediately or after taking an exam for certification. Chi square analysis did not note any significance between community, academic and combined programs regarding their opinions on whether or not graduates should perform HPB surgery $\left(X^{2}=5.233, P\right.$ $=0.2642)$.

\subsection{Resident and Faculty Participation in HPB Research}

In terms of surgical research in HPB, $61 \%$ of programs were involved in basic chart analyses. One to two faculty members were involved in HPB research in $52 \%$ of programs and $43 \%$ had residents actively completely research. Fifteen percent of programs had no faculty involved in research on any of the pancreatic, biliary, or hepatic systems.

\section{Discussion}

\subsection{General Competency of Graduating General Surgery Residents in $\mathrm{HPB}$}

This survey describes how $59 \%$ of general surgery PDs believes that their residents are capable of doing HPB surgery in practice without the need for fellowship, either completely independently or by passing a qualifying examination. With statistical 
analysis, these results did not differ significantly between community, academic, or combined residency programs. Qualitatively, fellowships were described in these survey results as "devastating to general surgery training" and "the wave of the present time". Frequent comments suggested that fewer HPB fellowships were needed, that HPB was integrated into surgical oncology fellowships, and that advanced training should be reserved for specific individuals. The PDs felt that their residents were most capable of performing common bile duct anastomoses and explorations, open or laparoscopic liver biopsies, and distal pancreatectomies, and these frequencies were not statistically different between academic, community, or combined residency programs. According to this study, $6 \%-13 \%$ of programs have residents performing more than 40 complex HPB cases in each of the three areas, hepatic, biliary, and pancreatic. This suggests that more cases are done in these residency programs than indicated by the AHPBA fellowship requirements, which are 25, 15, and 25, respectively (Appendix A).

4.2 HPB Patient Care beyond the Scope of Case Proficiency

The HPB curriculum of the AHPBA for fellowship training has been adopted internationally to standardize HPB training globally and provide high-quality education [3, 4]. Unfortunately, not all fellowship programs are able to meet the outlined specifications, and fellows fail to meet requirements [5]. This study suggested that HPB training in residency is considered adequate for practice by a majority of program directors. Even if not all PDs agree, modifications can be made to curriculums to support this concept. In this study, $66 \%$ of programs did not have an HPB service for their residents. This could be changed to increase HPB exposure in residency. Any further HPB training needs, such as intraoperative ultrasound and hepatic tumor ablation, could be factored into electives such as gastrointestinal imaging and oncology rotations, emphasizing total care of the HPB patient [1]. As HPB surgery is not only about procedures, focus could be placed on EPR (enhanced pathways for recovery), and perioperative management [6-8]. Certainly the results of this survey show that most PDs believe that chief residents are capable of a broad scope of HPB cases. HPB-specific rotations could also be of benefit regardless of HPB interest, as recent studies have shown that interpretation and application of intraoperative cholangiograms and endoscopic ultrasound is poor to mediocre among board certified surgeons $[9,10]$.

\subsection{Modifying General Surgery Curriculum for HPB Studies Functional Compromise to Fellowship}

Several studies would suggest that institutions with training programs provide better long and short term outcomes for HPB patients, and learning curves in treatments improve readily with higher volume [11-13]. HPB training in surgical residency, where the frequency and intensity of exposure is the greatest, prepares surgeons for HPB practice. Where general surgery residencies are meeting fellowship requirements for HPB training, HPB fellowship may not be the best route to higher learning. Modifications to general surgery curriculums could adequately meet any further requirements that the AHPBA might deem necessary to prepare general surgeons for HPB practice, especially as this survey suggests that residents are technically adept. As our survey suggests that in $67 \%$ of programs, less than $5 \%$ of chief residents were going into HPB fellowships, perhaps modifying general surgery programs would be a better place to start enhancing HPB instruction.

\subsection{Study Limitations}

This survey has many limitations. A response rate of 81 out of 250 PDs (32\%) falls within the normal range for web-based surveys [14]. In 2009, an online survey of British practitioners had a response rate of 28\% [15]. Better responses have come from in person visitations and clinic visits as well as other electronic methods 
such as text messaging [16, 17]. Some academics believe HPB specialization is necessary and others think the subject is sufficiently addressed in resident and other fellowships. This survey was insufficient in addressing all of those points. Furthermore, the opinion of PDs does not necessarily correlate to resident perspective on their own training [18]. Whether or not residents feel prepared to practice HPB surgery without further training was not reviewed in this survey. Despite the demand for the general surgeon, surgical trainees feel the need to go for further training [19]. The opinion of employers and fellowship directors on the abilities of new graduates was not within the scope of this survey. This survey could not assess the individuality of each general surgery residency for HPB training and exposure. Residents from different programs may have differing levels of confidence in HPB or other operative cases.

\subsection{Where Further HPB Training is Effective}

Despite the limitations listed above, this survey does point out that many PDs feel that residents are meeting fellowship training standards during residency, and that HPB fellowships are unnecessary. In our survey, $49 \%$ of PDs thought further HPB training was only necessary for those individuals interested in pursuing a career in HPB. Fifty-two percent of respondents did not believe that HPB fellowship were necessary to practice HPB in the community after graduation. Most respondents indicated that attention should instead focus on improving and expanding HPB training during general surgery residency to prepare graduates.

\section{Conclusions}

General surgery residents are performing more than the ACGME required number of complex HPB cases, even meeting HPB fellowships requirements. Current opinion amongst general surgery PDs suggests that general surgery residents getting more than the required number of HPB cases should be individually assessed for competence in HPB without the need for further training.

\section{References}

[1] American Hepatopancreaticobiliary Association. 2010. "Appendix to AHPBA HPB Curriculum." AHPBA. Accessed October 16, 2014. http://www.ahpba.org/hpb-fellowships.

[2] Daee, S., Flynn, J. C., Jacobs, M. J., and Mittal, V. K. 2013. "Analysis and Implications of Changing Hepatopancreatobiliary (HPB) Caseloads in General Surgery Residency Training for HPB Surgery Accreditation." HPB 15 (12):1010-5.

[3] International Hepato-Pancreato-Biliary Association. 2010. "International Hepato-Pancreato-Biliary Association (IHPBA) HPB Curriculum Page." Accessed March 1, 2013. http://www.ihpba.org/96_HPB-Curriculum.html.

[4] Pitt, H. A. 2006. "IHPBA Newsletter February." $H P B$ (Oxford) 8:75-8.

[5] Raptis, D. A., and Clavien, P. 2011. "Evaluation of Hepato-Pancreato-Biliary (HPB) Fellowships: An International Survey of Programme Directors." $H P B$ 13: 279-85.

[6] Coolsen, M. M., Wong-Lun-Hing, E. M., van Dam, R. M., van der Wilt. A. A., Slim, K., Lassen, K., Dejong, C. H. 2013. "A Systematic Review of Outcomes in Patients undergoing Liver Surgery in an Enhanced Recovery after Surgery Pathways." HPB (Oxford) 15 (4): 245-51.

[7] Hughes, M. J., McNally, S., and Wigmore, S. J. 2014. "Enhanced Recovery Following Liver Surgery: A Systematic Review and Meta-Analysis." HPB (Oxford) 16 (8): 699-706.

[8] Walters, D. M., McGarey, P., LaPar, D. J., Strong, A., Good, E., Adams, R. B., and Bauer, T. W. 2013. “A 6-day Clinical Pathway after a Pancreaticoduodenectomy is Feasible, Safe and Efficient." HPB (Oxford) 15 (9): 668-73.

[9] Yusuf, T. E., Harewood, G. C., Clain, J. E., Levy, M. J., Wang, K. K., Topazian, M. D., and Rajan, E. 2004. "Knowledge of Indications for EUS among Gastroenterologists and Non-gastroenterologists." Gastrointestinal Endoscopy 60 (4): 575-9.

[10] Sanjay, P., Tagolao, S., Dirkzwager, I., and Bartlett, A. 2012. "A Survey of the Accuracy of Interpretation of Intraoperative Cholangiograms." HPB 14 (10): 673-6.

[11] de Reuver, P. R., Grossmann, I., Busch, O. R., Obertop, H., van Gulik, T. M., and Gouma, D. J. 2007. "Referral Pattern and Timing of Repair are Risk Factors for Complications after Reconstructive Surgery for Bile Duct Injury.” Ann. Surg. 245 (5): 763-70.

[12] Mercado, M. A., Franssen, B., Dominguez, I., Arriola-Cabrera, J. C., Ramírez-Del Val, F., 
Elnecavé-Olaiz, A., Arámburo-García, R., and García, A. 2011. "Transition from a Low- to a High-Volume Centre for Bile Duct Repair: Changes in Technique and Improved Outcome." HPB (Oxford) 13 (11):767-73.

[13] Clark, W., Hernandez, J., McKeon, B. A., Kahn, A., Morton, C., Toomey, P., Mullinax, J., Ross, S., and Rosemurgy, A. 2010. "Surgery Residency Training Programmes have Greater Impact on Outcomes after Pancreaticoduodenectomy than Hospital Volume or Surgeon Frequency." HPB (Oxford) 12 (1): 68-72.

[14] Fox, M., Fox, C., Cruickshank, W., Penhale, B., Poland, F., and Steel, N. 2014. "Understanding the Dementia Diagnosis Gap in Norfolk and Suffolk: A Survey of General Practitioners." Qual. Prim. Care 22 (2): 101-7.

[15] Tikoo, M. 2012. "Assessing the Limitations of the Existing Physician Directory for Measuring Electronic Health Record (EHR) Adoption Rates among Physicians in Connecticut, USA: Cross-Sectional Study." BMJ Open 2 (e001066):1-6.
[16] Christie, A., Dagfinrud, H., Dale, Ø., Schulz, T. and Hagen, K. B. 2014. "Collection of Patient-Reported Outcomes;-Text Messages on Mobile Phones Provide Valid Scores and High Response Rates." BMC Med. Res. Methodol. 14: 52.

[17] MacLean, D. R., Petrasovits, A., Nargundkar, M., Connelly, P. W., MacLeod, E., Edwards, A., and Hessel, P. 1992. "Canadian Heart Health Surveys: A Profile of Cardiovascular Risk. Survey Methods and Data Analysis. Canadian Heart Health Surveys Research Group." CMAJ 146 (11):1969-74.

[18] Walton, J. M., and Patel, H. 2008. "Residents as Teachers in Canadian Paediatric Training Programs: A Survey of Program Director and Resident Perspectives." Paediatr. Child Health 13 (8): 675-9.

[19] Fitzgerald, J. E., Milburn, J. A., Khera, G., Davies, R. S., Hornby, S. T., and Giddings, C. E. 2013. "Clinical Fellowships in Surgical Training: Analysis of a National Pan-specialty Workforce Survey." World J. Surg. 37 (5): 945-52.

Appendix A: AHPBA advanced gastrointestinal surgery curriculum for HPB surgery fellowship [1].

\begin{tabular}{lll}
\hline AHPBA fellowship requirement & Description of fellowship requirement & Required number \\
\hline Unit 1-The liver & Resection of two or more segments, with a least 15 of these procedures being & 25 \\
major liver procedures & hemi-liver resections & Unroofing or sterilization of large or multiple hepatic cysts \\
& Ampulla or bile duct resection & 15 \\
Unit 2-The biliary tract & Transduodenal sphincteroplasty \\
major biliary procedures & Biliary anastomosis-intra-hepatic or extra-hepatic \\
& Resection for gallbladder carcinoma \\
& Resection \\
Unit 3-The pancreas & Tumor enucleation \\
major pancreatic procedures & Anastomosis (e.g., pancreaticojejunostomy) \\
& Drainage (e.g., pseudocyst procedure) \\
& Debridement/necrosectomy \\
Unit 7-Transplantation & Not required \\
& Can represent up to a maximum of 20\% of cases in each of three categories \\
& Minimum of 12 months \\
Additional requirements & Experience in intraoperative ultrasound \\
& Experience with minor HPB cases \\
& Experience in hepatic tumor ablation \\
Total number of cases & Experience in minimally invasive HPB staging and surgical procedures \\
\hline
\end{tabular}




\section{Perceptions of Program Directors on the Necessity of Hepatopancreaticobiliary Fellowships in Training General Surgery Residents}

Appendix B: Survey questions sent to PDs regarding perceptions towards HPB fellowships.

With what type of general surgery program are you involved?

How many residents does your program graduate each year?

Is there an HPB fellowship at your institution or closely affiliated with your institution?

How many members of your teaching faculty are regularly performing HPB surgeries?

Of the teaching faculty performing complex HPB surgeries at your institution, how many have been formally trained in an HPB fellowship?

Does your program dedicate a specific service or rotation in HPB surgery for your residents?

What type of research, if any, is your program involved regarding the pancreas, liver and biliary tract?

How many of your general surgery residents participate in research involving the pancreas, liver and biliary tract?

How many of your teaching faculty participate in research involving the pancreas, liver and biliary tract?

What percent of your graduating residents have shown interest in HPB fellowships in the past 10 years?

How many of your graduating residents have matched into HPB fellowships?

In which of their 5 years of training are your residents initially exposed to HPB cases?

In 5 years, to how many complex hepatic cases are your graduating residents exposed?

In 5 years, to how many complex pancreatic cases are your graduating residents exposed?

In 5 years, to how many complex biliary cases are your graduating residents exposed?

Which of the following complex biliary surgeries do you feel your graduating residents are capable of performing comfortably?

Which of the following hepatic surgeries do you feel your graduating residents are capable of performing comfortably?

Which of the following pancreatic surgeries do you feel your graduating residents are capable of performing comfortably?

In which of the following ways would you characterize the need for current HPB fellowships?

Do you feel that residents that meet certain numbers of HPB surgery during their 5 years of general surgery residency should automatically be certified in HPB surgery?

What role do you feel HPB fellowships will play in the future? 